\title{
Institutional Ethnography and Surveillance Studies: An Outline for Inquiry.*
}

\author{
Kevin T. Walby 1
}

\begin{abstract}
Institutional ethnography (IE) is a method of inquiry that problematizes social relations at the local site of lived experience, while examining how sequences of texts coordinate consciousness, actions, and ruling. I argue that institutional ethnography is a critical method of inquiry useful for revealing and reshaping the textual organization of surveillance. Central issues regarding institutional ethnography as a method of inquiry, including standpoint(s), texts and institutions, interviewing, and mapping, are discussed. Researchers studying surveillance would benefit from engaging with the method of institutional ethnography during future research because IE has a unique ability to explicate how surveillance subjects are linked to and managed by discursive, managerial, and professional forms of power.
\end{abstract}

\section{Introduction}

The emerging transdisciplinary field of surveillance studies suffers from an overabundance of speculative theorizing and a dearth of rigorous empirical research. Of course, many monographs, articles, and reports tangentially related to the study of surveillance are based on social scientific practice, and many of the classic works that constitute surveillance studies itself are not purely speculative but engage through research with the social world they investigate (see, for instance, Rule, 1973; Braverman, 1974; Marx, 1988). Researching surveillance involves "watching" and needs to be accompanied by an ethics of honesty, sympathy and respect as it regards researchers and their respondents. Still, there is no overarching method in this area of study. Nor should there be only one overarching method. When we use the word "surveillance" we often forget how amazingly diverse the forms, linkages, and processes captured by the word are. That surveillance is a signifier referring to face-to-face supervision, camera monitoring, TV watching, paparazzi stalking, GPS tailing, cardiac telemonitoring, the tracking of commercial/internet transactions, the tracing of tagged plants and animals, etc., points to an impossible and always receding signified. Nevertheless, we need to refer

\footnotetext{
* The impetus to write this paper on method was gained at the 'Theorizing Surveillance: The Panopticon and Beyond' workshop, Queen's University May 12-14, 2005. In addition to the two anonymous Surveillance \& Society reviewers, I would like to thank Dorothy E. Smith, Aaron Doyle, Andrea Doucet, Dale Spencer and the editors for their insightful comments on earlier versions of this manuscript.

1 Department of Sociology and Anthropology, Carleton University, Ottawa, Ontario, Canada, mailto:kwalby@connect.carleton.ca
} 
to these processes, and at present time surveillance is the term. We also need ways of inquiring into these processes. The search is on for the methods of inquiry needed to give surveillance studies continuity and legitimacy in the sport de combat of social science.

Institutional ethnography (IE) is a method of inquiry that problematizes social relations at the local site of lived experience, while examining how sequences of texts coordinate actions, consciousness, and forms of organization extra-locally (Smith, 1987). Institutional ethnography's focus on texts is what allows it to investigate beyond the ethnographic and locally observable into the extra-local relations that permeate and control the local. Interestingly enough, however, IE emerged as a critique of traditional sociology and the social scientific approach traditional sociology was/is based on. It may therefore strike one as odd that in this paper I am arguing that institutional ethnography should play an important role filling in the "methods gap" all too apparent in contemporary work on surveillance. I maintain that IE is both a critique and a method of sociological inquiry however much it differs from the systematic (and objectifying) techniques of traditional sociology. ${ }^{2}$

This paper is organized in three sections. In the first section, I discuss surveillance at a general level, conceptually locating the practices and processes characteristic of surveillance, and why it is important to be clear about these practices and processes for the purpose of research. I delimit the types of surveillance discussed to those into which institutional ethnography is suitable for inquiring. Second, I explain what IE is and how one might go about doing an institutional ethnography. I discuss the central issues regarding institutional ethnography as a method of inquiry, including standpoint(s), texts and institutions, interviewing, and mapping. In the final section, drawing from my own work (see: Walby, 2005, 2006), I demonstrate one way institutional ethnography can be put into surveillance studies practice.

\section{Making Sense of Social Monitoring}

While it is uncomplicated to list and describe a multiplicity of surveillance processes, it is more difficult to come to some agreed upon definition of what surveillance is. Marx's (2005, 2001) iterant aide memoires concerning a series of analytically and methodologically rigorous research elements are certainly significant. Surveillance today is generalized, dispersed and extensive; however, in line with Marx's reasoning, we need be more specific if earnest about devising stratagem for studying surveillance.

\footnotetext{
2 For Smith (1987: 54), traditional sociology is part of the ideological structure that "orders, organizes, and sanctions the social relations that sustain domination". Traditional sociology objectifies the society it analyzes, and abstains from implicating the consciousness of ruled classes in its knowledge organizing practices. What Smith calls the "line of fault" develops between the experiential-embodied consciousness part of one's everyday world and the discursive consciousness that organizes ruling. A bificuration of consciousness exists for those at this line of fault, where they must do routine work and organize their daily life under conditions not of their choosing, yet sometimes participate in the peculiar out-of-body modes of consciousness specific to the ruling relations. Traditional sociology takes for granted the subordinated tasks the underclass have been compelled to perform, even though it is these very tasks that liberate the ruling classes from having to attend to their needs in the concrete. Knowers are cancelled from traditional sociological discourse. Such positionless accounts depend upon and transmit the institutional order from which they originate (Smith, 1999: 51).
} 
Contemporary collation of data can be depicted in terms of the space and capture of flows - flows of people, commodities, and electronic information that annihilate traditional time/space boundaries. Castells $(1996,2000)$ writes of the network society, enabled by light-speed information technologies, where the pace of information flows alters the former sequential order of phenomenon and aims toward instantaneity. Networks are open structures, can expand without limit, and are the necessary instruments for a decentralized and global capitalist economy.

Flows, however, circulate and are captured according to logics embedded in asymmetries of organizational power (Lyon, 2003). Claims arguing that "surveillance has become rhizomatic, it has transformed hierarchies of observation, and allows for the scrutiny of the powerful by both institutions and the general population" (Haggerty and Ericson, 2000: 617; see also: Urry, 2003: 115) need to be set against the continued existence of centralized institutions serving as sites for the unification of regulatory surveillance projects. That surveillance has become horizontal instead of hierarchal cannot be assumed a priori (Hier, 2003), and every social monitoring project deserves to be accorded both inductive and deductive research attention.

Regardless of how instantaneous they have become, flows of information eventually manifest themselves in actual and multiple locations - what in this paper I will call a contact point (Ball, 2005) - where information about a surveillance subject becomes accessible to a surveillance agent in the form of a text, form, file, dossier, etc., be it in paper or digital format.

The connection between surveillance subjects and agents is mediated through various technologies, most notably through commonplace forms of texts. Texts refer to words, images, or sounds that are set into a durable material form of some kind that can then be read, seen, heard, or watched (Goody, 1986). What I am calling a "text" is what for Weber (1968) are the dossiers constitutive of bureaucratization, and what for Foucault $(1985,1979)$ are the constituents of rational knowledge systems through which bodies are administered. For both Weber and Foucault, information regarding a subject population is collected by some agent or agency, stored in potentia using filing and sorting systems, and sometimes used in the future to administer that subject population. Bureaucratic administration, for Weber (1983), was a product of the rationalization process. Prioritizing the function of paper dossiers in the administration of the state, Weber saw the accumulation and centralization of information about embodied persons as fundamental to the execution of state power. A similar process is evident in Foucault's discussion of the medicalization of epidemics in France. An all-encompassing discourse of medicalization occurred vis a vis the creation "in every large town of a 'government health centre' and in Paris of a 'health court', sitting beside the National assembly, centralizing information, conveying it from one part of the country to another" (Foucault, 1985: 196, emphasis added). The emergence of these systems of knowledge that operate on the bodies of surveillance subjects are in debt to the development of printing and text reproduction.

An important point to tease out of Foucault's above words is that information is "conveyed" to various agencies in a very plain way. Texts are actual material things, written and read in the same place and time as the writer or reader engages with them, and 
then sent to various other readers or writers who work with the textual information. This is what I will call here the material relations of surveillance. The material relations of surveillance are human relations mediated by texts that coordinate social monitoring practices and enhance, transform, and/govern surveillance subjects. The material relations of surveillance may also be discursive, ideological, affective, productive of and contingent on subjectivities, but will still have a tangible base of textual practices that can be located and inquired into. Information is collected, sorted, and sent, literally, by the work of people. Work, generously defined, is anything that takes time/energy and is done in definite places in relation to actual people. The material relations of surveillance are the actual conveyances of physical texts that sustain distanciated surveillance relationships between human beings.

I have in this overview of surveillance practices delimited the types of surveillance discussed to those into which institutional ethnography is apposite for inquiring: surveillance activities involving various forms of texts existing in a circuit of surveillance involving human surveillance agents at one end of the circuit and human surveillance subjects at the other. The circuit is always spiraling, never completed, and traverses other circuits in which the surveillance subjects and agents partake. This work-text-work circuit is only finished when, for instance, in the case of military surveillance, the logic of the work is to destroy the surveillance subject. I now discuss the central issues regarding institutional ethnography as a method of inquiry.

\section{Institutional Ethnography and Surveillance Studies}

\section{Standpoint(s), Method of Inquiry, and Methodology}

Both a critique and form of sociology, Dorothy E. Smith's contributions to understanding the social organization of knowledge in contemporary societies are invaluable. Embedded firmly in a Marxian ontology of the social that sees individuals as real and relationally producing their own conditions of existence, Smith shows how knowledge is socially constituted and that whatever is brought into being is done so by people "at work" (Smith, 1999: 75). Smith's focus on how discursive, managerial, and professional forms of governance (here after referred to as the ruling relations) lift women specifically and people generally out of their embodied/local ways of knowing and leads to a bifurcation of consciousness is a radical insight. One can immediately recognize the affinity between Smith's (1999: 49) definition of ruling as "discursive, managerial, and professional" and the material world of surveillance processes organized by forms of writing, inscribing, reading, and interpreting information.

Smith's work is a sociology for people (see: Smith, 2005), and numerous standpoints can be taken up. By taking the standpoint of the surveillance subject, by inquiring into "the social" a propos the everyday problematics surveillance subjects experience via their interactions with surveillance agents and agencies, researchers can explicate the social organization of knowledge behind monitoring practices and potentially reshape or subvert them. The binary division of surveillance subject/agent is artificial but heuristically useful for conceiving of how surveillance relations are put together. How do social monitoring processes lift subjects out of their everyday life through discursive, managerial and professional activities? How are subjects disembodied and represented as code in ways 
that become enabling or restricting for them? How can the discursive, managerial and professional activities associated with surveillance be re-configured to better implicate the consciousness of surveillance subjects in those activities? Questions like these are only examples of problematics that must emerge from the surveillance subject's experiences in her/his interaction with various agents and agencies, and must not be pre-fathomed by the institutional ethnographer. Problematics can emerge from the ethnographer's own life, and, in this sense, some of the best institutional ethnographies emerge out of activism.

It should be clear that institutional ethnography is not simply a methodology. IE is not a tool one can readily use at will without adopting the theoretical framework implicit in each inquisitive move the institutional ethnographer makes. Part of learning this approach is learning Smith's approach to social inquiry. Theory and method are intricately entwined in institutional ethnography and cannot be divorced from one another.

\section{Active Texts and Institutions}

Participants in the material relations of surveillance are connected through texts and the organizational features that envelop work processes. Texts hold and generate power in our society (Smith, 1992: 93), and the physicality of texts is fundamental to institutional organization (Smith, 1984). Texts transport the observations and discriminations of surveillance agents from one setting to another, at the same time that the particularities of the surveillance subject disappear into the discursive. They carry informational messages that can appear at many times in many places. Texts - physical things located in the same locales as the embodied text activators - are active constituents of social relations and are the means by which work and social activity is coordinated beyond the particular local setting of reading/writing (Smith, 1999: 80). However, it is only at the local site of experience and text activation that these forms of organization can be inquired into (ibid.: 93). The local site is where people work with texts. Institutions are put together by various people working with texts in different locations, and are therefore connected by worktext-work sequences.

The texts involved in surveillance processes are considered as active in coordinating assemblages of sociality and work across numerous institutional settings. There is always something in the text that, existing in potentia, enters into the organization of what is to come (Smith, 2001: 174). Surveillance-generated texts do not achieve their capacity to enable, transform, and regulate just by existing. That the text is active necessitates its reading and activation by a worker of the text (i.e. the surveillance agent). Activation of a text is bound up in the interpretative and subjective processes of human consciousness, reading, and action:

That it is activated by the reader means that the activity or operation of the text is dependent upon the reader's interpretative practices. These too are constituents of social relations rather than merely the idiosyncrasies of individuals (Smith, 1990: 121).

This interpretative and discriminatory aspect is an unfailing characteristic of social monitoring. Activation is therefore informed by a subjective reading that has in part been structured by institutional discourses and other informal socialization processes. Of course, texts are activated in different ways at different times and places. Each text 
activator comes to the text with a particular set of interpretative skills and subjectivities. The focus on texts should not imply that there is something homogeneous about all surveillance situations. Rather, the interesting point of analysis is how the variable activation of standardized texts in diverse settings is constitutive of ruling and surveillance relations. Text-mediated work activities of surveillance agents are a point of entry for understanding how the material relations of surveillance are organized.

Institutions identify a text-mediated "complex of relations forming part of the ruling apparatus, organized around a distinctive function", and ethnography commits us to an exploration from the perspective of "the persons whose everyday world of working is organized thereby" (Smith, 1987: 160). Institutions are constituted by universalizing or objectifying discursive practices that coordinate people's diversity of experience and interest into a unified frame at the extra-local level (Smith, 1999: 196). Therefore, IE draws on Marx and his conception of political economy arising from the activities of people (Smith, 1990: 94), but also on ethnomethodology, because the institutional ethnographer starts from the common-sense knowledges of people and how they talk about their work.

The idea of texts as constituents of organizations has been around in institutional theory for a long time. Goody (1986) acknowledged the durability of written texts compared to speech and oral interaction. DiMaggio and Powell (1983) argued that texts are important mechanisms in the mimetic homogenization of organizations, allowing for organizations to standardize by modeling themselves after similar organizations which are perceived as legitimate or efficient. ${ }^{3}$ For Taylor and colleagues (see: Taylor et al., 1996; Taylor and Van Every, 1993), actions in bureaucratic organizations are always text generating. Texts allow for multiple readings by multiple individuals and the configuration of ideas across time and space. Hasslebladh and Kallinikos (2000: 703) assert that "no organization could support its status as a formal system without the arsenal of verbal and numerical techniques through which its goals and operations are described, organized and controlled".

More recently, Phillips et al. (2004: 635) have offered what they call a "discursive model of institutionalization," where "it is not action per se that provides the basis for institutionalization but, rather, the texts that describe and communicate those actions. It is primarily through texts that information about actions is widely distributed and comes to influence the actions of others". The same authors (ibid.: 641) write that "discourses provide the socially constituted, self-regulating mechanisms that enact institutions and shape the actions that lead to the production of more texts. Thus, the discursive realm acts as the background against which current actions occur-enabling some actions and constraining others". However, a problem emerges here. Purged from this structuralist version of institutional theory's idea of texts as constituents of organizations are the actual human beings who activate the texts. Without an ethnographic focus on people who do

3 Textual standardization and connectedness is not the only mechanism of institutional isomorphic change. In addition to mimesis, coercive isomorphism and normative isomorphism take place. These three mechanisms are by no means mutually exclusive. Coercive isomorphism refers to formal and informal pressures exerted on organizations by other organizations (i.e.: direct imposition of rules), while normative isomorphism refers to the rise of professionals in organizations and pressure to professionalize (DiMaggio and Powell, 1983: 150-152). 
the work of reading, interpreting and inscribing texts, we are left with a monolithic notion of discourse determining the bounds of agency. This reinforces the fact that institutional ethnography is not simply an approach one can adopt in small parts by saying "let's focus on texts". Rather, IE as method is important because it situates individuals in the complexity of their lived realities and draws from their experiential knowledge of those realities to show how sequences of texts coordinate actions, consciousness, and forms of organization extra-locally.

\section{Institutional Ethnography and Qualitative Methods}

Institutional ethnography differs from other methods of qualitative inquiry in how it links experience or accounts in a particular way to webs of sociality and work. IE explicates the relations between extra-local institutions, but asserts that in order to do this one must explore the everyday work-text-work activities done by actual people in their local settings. The institutional focus is often ignored, and thus institutional ethnography is sometimes lumped together with nominalist qualitative methods ${ }^{4}$ that tend not to advance inquiry past the consciousness of the particular subject. Conversely, IE is always concerned with individuals in relations with each other and with institutions. Institutional ethnography maintains a social ontology of the subject based in what people do, how they work, and how this doing and working hooks up with others in a web of ruling that is, increasingly, mediated through surveillance texts. It is in this sense that institutional ethnography can contribute to the development of methodological rigor in surveillance studies.

\section{Interviewing and Analysis in IE}

Institutional ethnography relies on interview transcripts, observations, and secondary documents as data. Institutional ethnography, however, differs from other forms of ethnography because it treats those sources of data not as the object of interest, but as an entry point into webs of sociality and work (Campbell, 1998: 57; but see also: Hammersley and Atkinson, 1983). Pace nominalist methodologies, in institutional ethnography the respondent is not a resource or topic in and of herself/himself. Rather, her/his experiences make evident to the researcher the organizational arrangement of the institution. According to Smith (2005: 135-139), the research process in institutional ethnography occurs through a number of intersecting experiential dialogues. The primary dialogue is between the interviewer and her/his respondents. Institutional ethnographers are aware that their own subjectivity has effectivity in research situations, and so are reflexively monitoring at all times their own position as subject in relation to the presence of the interviewee. A secondary dialogue occurs between the institutional ethnographer and the transcript of the audio recorded interview or the field notes. It is often in the secondary dialogue where the interviewee's experience as a subject and the traces of organization present in their experience become apparent.

Asking a respondent how they work with texts or how they are the subjects of surveillance can explicate the way surveillance reaches down into people's lives and

\footnotetext{
4 For instance, a great deal of phenomenological investigation begins with individual consciousness but stops short of analyzing how consciousness is socially organized. Analyzing the meaning of experience from the perspective of participants through focusing on any experience that presents itself to consciousness does not render the organization and conditions of that meaning examinable (Smith, 1987: 86).
} 
connects up with extra-local, institutional processes. The talk of text activators (surveillance agents) in their work settings demonstrates how surveillance texts are worked with to coordinate lived realities and facilitate extra-local organization. In interviewing it is important to listen for and ask about (Devault and McCoy, 2002: 765) texts or sequences of texts which are the constituents of social relations. Interrogating this process at various contact points exposes both the subjective aspects of reading/writing involved in police text production as well as the extra-local institutions the text hooks up with and connects into the surveillance circuit. Texts are produced within a particular interpretative-institutional frame, and because the ethnographer is located in the workplace during the interviews (i.e.: the police cruiser, the booking room) and can sometimes view the same text as the surveillance agent, it is possible to examine how different interpretations of the text could be made by observers foreign to the organizationally-situated ruling relations.

The institutional ethnographer should conduct interviews outside of the initial work location, and would ideally interview the agents and subjects of surveillance in addition to those persons in institutions that are drawn into the surveillance circuit through the writing, reading, sending, receiving, of texts integral to the process. Put another way, interviews are ideally to be conducted with 1 . s/he who brings the text(s) into the surveillance circuit, 2 . those who in other locations take the text(s) up in a subsequent phase of work activity, and 3. s/he whose relation to the institution(s) is mediated or regulated by virtue of being the surveillance subject.

\section{Mapping: A Technique for Explicating the Material Relations of Surveillance}

Once the institutional ethnographer has elicited from the talk of her/his respondents the way a sequence of texts is worked with to organize relations between individuals and institutions and institutions themselves, it is possible to construct a map of exactly what texts are involved, where they go in the surveillance circuit, and how they connect back to the administering/coordinating of everyday life. Figure 1 is an example of how the mapping technique may look when completed. One institutional ethnographer could focus more specifically and ethnographically on the intimacies of work-text-work processes. Another could focus more generally on the perhaps hundreds of connections to be made with extra-local institutions. The orange shapes represent people (surveillance subjects or agents). The yellow ovals represent the work surveillance agents do and the results of their work. The green boxes represent the various texts involved, and the blue boxes are the institutions which the texts connect in the relations of surveillance.

This circuit begins with the surveillance subject. The problematic being inquired into emerges from her/his everyday life and the story s/he tells the institutional ethnographer about her/his textual relationship to various institutions. The surveillance subject's appearance, actions, and gestures become information, either willingly or passively through extraction by some surveillance technique. This information is "produced" by the surveillance agent when appearances and/or actions are written in words or numbers into a file, text, or item in a database. At a contact point, the information is activated by a surveillance agent, sorted in some way, interpreted against the other files or items. The surveillance agent translates the information from the primary text into a sequence of 
generated texts. This interpretative work of text activation can be inquired into through interviewing the surveillance agent.

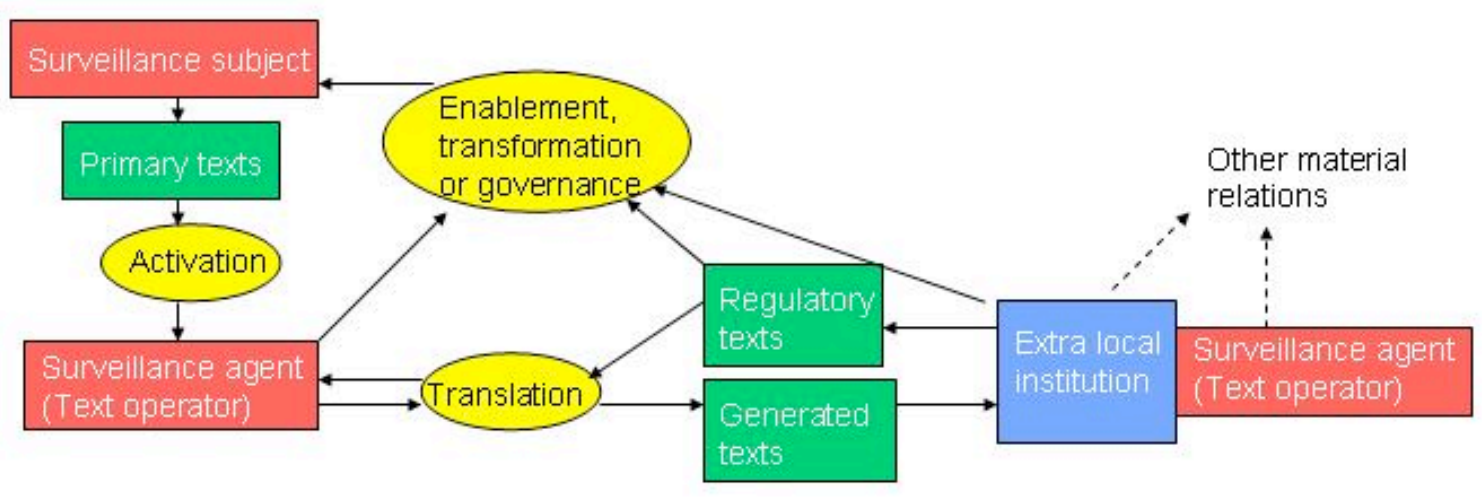

Figure 1: Mapping the Material Relations of a Surveillance Circuit

The "actual" of the surveillance subject's everyday life is "produced" by the work of the surveillance agent. How the surveillance agent does this is elicited from their talk about their work. It may be that the surveillance agent has a regulatory text that shapes how s/he sorts and translates the different files. When synchronized by this regulatory text, it is possible to see that the surveillance agent's actions are expressions of the organizational properties constitutive of the institution where s/he works (i.e.: security firm, health insurance sales agency). The translated texts are then "conveyed," through email or regular post, to various other extra-local institutions (i.e.: police, courts, insurance industry brokers). Actual people cooperate in similar types of work-text-work activities at these extra-local institutions. How they read, write, and transmit texts is also explicated using this approach. There may be numerous surveillance agents in an institution that circulate the text through intertextual circles, and each agent should be interviewed to see how the surveillance circuit is put together through their work.

The result of this process can be the enabling, transforming, or governing of the surveillance subject. However, the circuit is never completed. Sometimes information is collected/extracted and is stored in potentia for months or years. It still must be activated. Sometimes information spills out of the circuit and into another, generating a subsequent set of surveillance relations. Moreover, surveillance agents are at the same time surveillance subjects and vice versa in other material relations of surveillance. No one is ever outside surveillance relations; no one is ever "surveillance free". But we can change how we interact in these relations. As Rule et al. (1980) pointed out long ago, the key to impeding intensified surveillance comes from the fostering of a less discriminating and less efficient relationship between organizations and their clientele. 


\section{Putting IE into Surveillance Studies Practice}

In my own work on private closed circuit television (CCTV) camera surveillance in Victoria, British Columbia (see: Walby, 2005, 2006), I conceptualize CCTV video as a televisual text that overlaps with non-televisual texts to act as a constituent of social relations. Research was conducted with camera operators in three settings: a suburban mall, a Campus Security CCTV control room and an office within a public housing complex. In these ethnographies, I interviewed CCTV operators in their work settings while they organized surveillance relations in their locales and did the work of CCTV video watching. The talk of CCTV operators (surveillance agents) in their work setting reveals how video is used to coordinate lived realities and facilitate extra-local organization. Operators read the screen and the bodies coming in and out view. Through interpreting visual cues, operators discriminate suspicious from non-suspicious using a set of working rules. These rules are a property of both their own subjectivity and the organization of which they are a part.

Video texts are active constituents of the relations between surveillance subjects, surveillance agents, and authorities representing extra-local institutions. First, CCTV operators can read the video as a "rolling text" that informs coordination of security activity in the immediate setting. Immediately coordinated activities can involve making arrests, deterring shoplifting or vandalism, etc. Second, the video text can be transcribed into a sequence of written "initiating texts" - logbooks, incident reports - that overlap and come to inform work processes far removed from the locale where the televisual data was gathered. Translating the video text into a written text requires the work of interpretation and translation - activation of the video text. Written texts are forwarded to various extralocal agencies (police, courts, etc.). The sequence of texts that reaches down into shopper's, resident's, and student's (surveillance subjects) lives and connects up with larger institutional and policing processes starts with the work of the surveillance agent (CCTV operator), as s/he reads the CCTV video text.

The material relations of surveillance, in this circuit, are the physical conveyances of text between different institutions in a way that organizes the work and consciousness of the surveillance agent, coordinating the relationship between the surveillance subject and the extra-local institution. Figure 2 demonstrates the coordinating role of televisual and non-televisual texts at a Suburban Mall (see: Walby, 2005). Again, viewing video as a "rolling text" of embodied surveillance, examples of who/what the surveillance agents deemed suspicious are people with worn-out shoes, people with inexpensive eye glasses or clothes, people with large and open bags like purses/backpacks, single women with baby carriages, and people with darker colored skin (especially Aboriginal youths). In the primary dialogue between the CCTV operators and myself, only the racialized profiling was apparent, but in the secondary dialogue between myself and the interview transcripts the range of elements deemed suspicious by the surveillance agents became more apparent. ${ }^{5}$ The CCTV operators activate the video text, make citizens' arrests, and

5 To reiterate what was written above about interviewing and analysis, the primary dialogue emerges from the research encounter between the institutional ethnographer and the person in their work setting, whereas the secondary dialogue emerges as the institutional ethnographer engages with the materials produced from the conducted interviews (Smith, 2005: 142). The moment of transition from primary to secondary dialogue is when what the people have told to the institutional ethnographer in conversation is reproduced 
translate the video into a written text. This written text, or "initiating text," takes the form of the logbook, and, in more serious cases, an incident report. Video of offenders can also be freeze-framed and distributed to other stores as a picture text, and the video itself is sent to Crown Counsel, the defense attorney, and the Court. The incident report also goes to Crown Counsel, the defense attorney, and the Court.

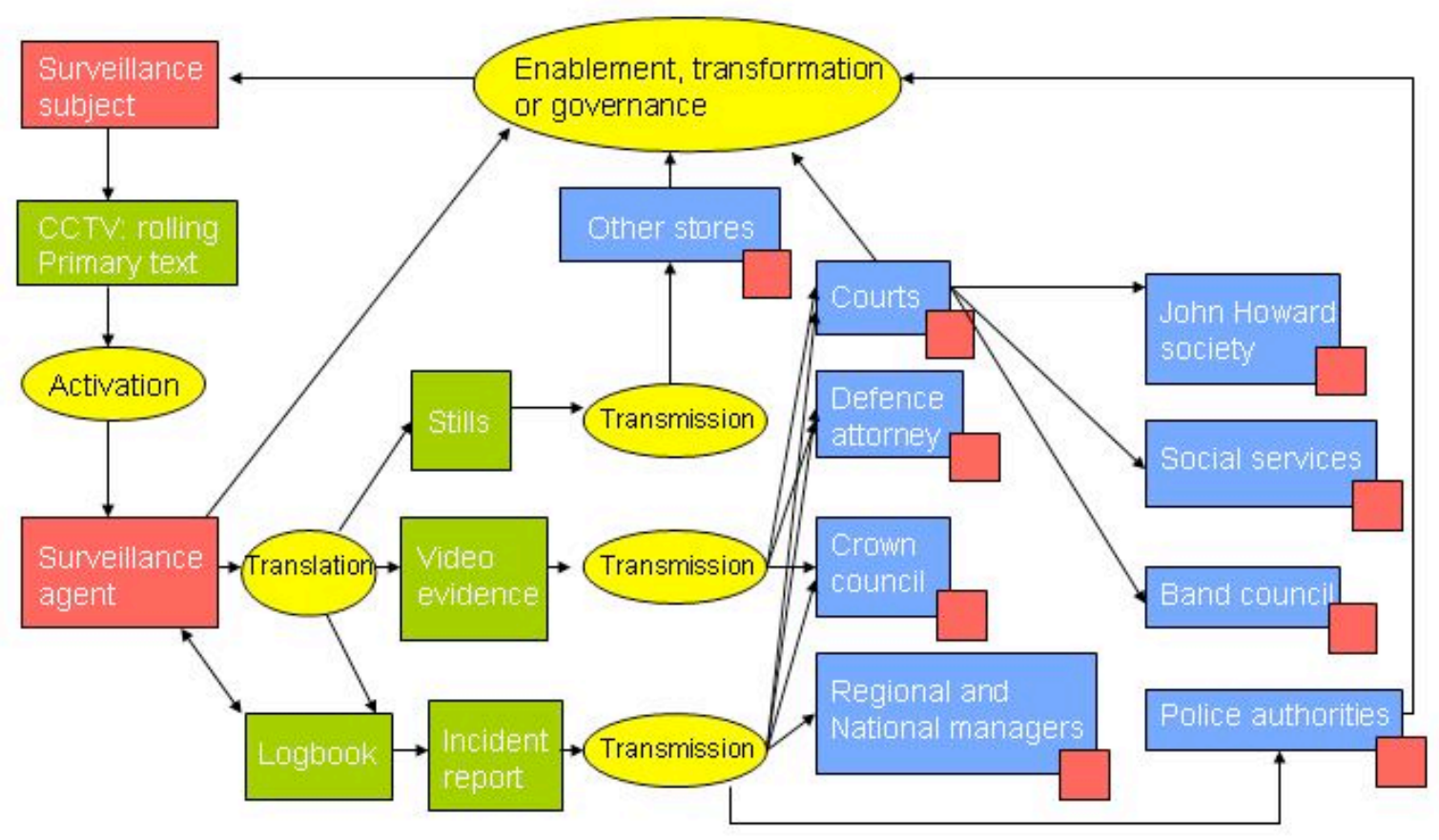

Figure 2: Co-ordination of televisual and non-televisual texts at a suburban mall

The Court can then distribute the incident report to the John Howard Society, Social Services, or the Band Council, depending on the given situation. The same copy of the incident report can be sent to the retail outlet Regional Manager in Vancouver, the retail outlet National Manager in Toronto, and Police authorities. The intertextual circle connecting these institutions is a surveillance circuit grounded in the materiality/replicability of texts. Again, it was only in the secondary dialogue between myself and the interview transcripts that the way in which the text was coordinating relations between different organizations and governing the surveillance subject was revealed.

The advantage of institutional ethnography for researching the textual organization of public and private camera surveillance is that it interrogates the interpretive work of the surveillance agent, the practical use of technologies in the workplace, and how this coordinates social relations inside and outside of the organization. Heath and colleagues (Heath, Luff, and Svensson, 2002; Heath, Hindmarsh and Luff, 1999) have examined how surveillance agents working in the London Underground interpret the conduct of traveling

as an interview transcript. As Smith (2005: 143) suggests, this interview transcript is not reinterpreted from an outsider theoretical frame, but is reassembled to locate a social organization of knowledge and practice in which the experiences of the interviewee, as told to the institutional ethnographer, are embedded by not wholly visible. 
persons in organizationally relevant ways, shaping the course of action between staff and passengers and staff themselves. Heath's studies do not examine how extra-local institutions are textually connected to these material relations of surveillance which have constitutive effects for surveillance subjects. Norris and Armstrong (1999) and McCahill (2002) have done similar ethnographic work, and although these reports are better able to account for system integration involving police agencies, other extra-local agencies involved in governing the surveillance subject are left out of the picture. Such studies do not trace the movement of televisual texts in original and/or transcribed form outside of the locale in which the textual information was gathered, and thus preemptively circumscribe inquiry into how these material relations of surveillance actually transpire.

Of course, IE as a method of inquiry can be applied to surveillance relations not involving CCTV video texts. Video texts are probably the exception and not the rule. Lyon's (2001: 42) concept of the "leaky container" is informative for making this point clear. The leaky container concept refers to situations where textual information "spills" out of one container (i.e. tax returns, driver's licenses, insurance policies, utility bills, lease agreements, health care files, purchase records, education records, etc.) and into another by virtue of extending a common technological system. When databases are merged, information is shared. Information is not a figurative or metaphorical referent but an artifact pointing to the product of reading and writing texts, to the tangible fruits of the material relations of surveillance. In contemporary society, surveillance subjects voluntarily divulge the bulk of information used to enable, transform, and administer them (Gandy, 1993). When one fills in a form or file, whether on paper or on-line, that information goes somewhere, and is worked with by various people. But where does that information go, who works with it? Have aspects of lived reality become lost in the translation of "your data" into a standardized, professional discourse? How is it that the bodies and information of the body politic are increasingly employed as an instrument of governance over against themselves? As I have argued, IE is a method that analyzes the material processes of how people interpret, compose, and send texts, thus allowing surveillance studies researchers to locate and explicate the extra-local surveillance relations that saturate and govern the local.

\section{Conclusion}

The material relations of surveillance discussed in this paper are an always open circuit that is completed by a human on both ends, where files in databases, forms, dossiers, records, reports, etc., connect the surveillance agents and subjects. That the circuit is open means that the circuit never ends and it overlaps with other surveillance activities. The institutional ethnographer can enter the points of contact in the circuit where texts are created, translated, forwarded, interpreted, in order to explicate how surveillance processes connect down with the local and connect up with various institutions.

In my research, I have interviewed only agents of surveillance, and have not conducted interviews in any of the secondary institutions drawn into the material relations of surveillance. Therefore, the research reported on here should be understood as an incomplete exploration of the outline for inquiry I have proposed. Future research must conduct interviews with surveillance subjects as well as surveillance agents, and conduct 
interviews in these secondary institutions, for such dialogues will more fully explicate how local surveillance activities connect the local to extended social relations of ruling that involve the enablement, transformation and/or governance of surveillance subjects. Finally, my approach specifically and institutional ethnography generally requires a more complex theory of the subject in the sense of how people are through their own actions engaged in the reproduction of surveillance organizations and the ruling practices carried out therein.

Until all material relations of surveillance become an exchange between artificially intelligent machines, there will be a need to explore and examine those surveillance activities constituted by a surveillance circuit with humans on both ends and textmediation in between. Surveillance researchers should focus on the text-mediated interactions made between surveillance agents and surveillance subjects at various points of contact in the surveillance circuit, and this entails interviewing surveillance subjects to understand the informationization of their bodies, interviewing surveillance agents who work with texts, and mapping the transmission of the text to various extra-local institutions. Ignoring the material relations of surveillance in future research will in no way aid the formation of new surveillance relations, and in fact would vouchsafe the contemporary association of surveillance with ruling practices. Apt to explicate and map the material relations of surveillance circuits, and particularly those relations of surveillance constituted by the reading, writing, and sending of dossiers, files, and other forms of text, institutional ethnography can contribute to the development of methodological rigor in the emerging sub-discipline of surveillance studies.

\section{References}

Ball, K. (2005) Organization, Surveillance and the Body: Towards a Politics of Resistance. Organization, 12(1): 89-108.

Becker, H. S. (1998) Tricks of the Trade: How to Think About Your Research While You are Doing It. Chicago: University of Chicago Press.

Braverman, H. (1974) Labour and Monopoly Capital: The Degradation of Work in the Twentieth Century. New York: Monthly Review Press.

Campbell, M. L. (1998) Institutional Ethnography and Experience as Data. Qualitative Sociology, 21(1): 5572.

Castells, M. (2000) Materials for an Exploratory Theory of the Network Society. British Journal of Sociology, 51(1): 5-24.

Castells, M. (1996) The Rise of the Network Society. Oxford: Blackwell.

Denzin, N. K. and Y. S. Lincoln. (2000) Handbook of Qualitative Research, $2^{\text {nd }}$ Edition. Thousand Oaks, CA: Sage.

Devault, M. and L. McCoy. (2002) Institutional ethnography: Using interviews to investigate ruling relations. Gubrium, J. F. and J. A. Holstein (eds). In Handbook of Interviewing: Context and Method. Thousand Oaks, Calif.: Sage Publications.

DiMaggio, P. J. and W. W. Powell. (1983) The Iron Cage Revisited: Institutional Isomorphism and Collective Rationality in Organizational Fields. American Sociological Review, 48(2): 147-160. 
Foucault, M. (1985) The Birth of the Clinic: An Archaeology of Medical Perception. New York, NY.: Vintage Books.

Foucault, M. (1979) Discipline and Punish: The Birth of the Prison. New York: Vintage Books.

Gandy, O. H. (1993) The Panoptic Sort: A Political Economy of Personal Information. Westview Press: Boulder, Co.

Goody, J. (1986) The Logic of Writing and the Organization of Society. Cambridge: Cambridge University Press.

Haggerty, K. D. and R. V. Ericson. (2000) The Surveillant Assemblage. British Journal of Sociology, 51(4): 605-622.

Hammersley, M. and P. Atkinson. (1983) Ethnography: Principles in Practice. Routledge, London.

Hasslebladh, H. and J. Kallinikos. (2000) The Project of Rationalization: A Critique and Reappraisal of Neo-Institutionalism in Organization Studies. Organization Studies, 21(4): 697-720.

Heath, C., P. Luff and M.S. Svensson. (2002) Overseeing Organizations: Configuring Action and its Environment. British Journal of Sociology, 53(2): 181-201.

Heath, C., J. Hindmarsh and P. Luff. (1999) Interaction in Isolation: The Dislocated World of the London Underground Train Driver. Sociology, 33(3): 555-575.

Hier, S. P. (2003) Probing the Surveillant Assemblage: On the Dialectics of Surveillance Practices as Processes of Social Control. Surveillance \& Society, 1(3): 399-411. http://www.surveillance-andsociety/articles1(3)/probing.pdf

Lemert, C. (1992) Subjectivity's Limit: The Unsolved Riddle of the Standpoint. Sociological Theory, 10(1): 63-72.

Lyon, D. (2003) Technology vs. 'Terrorism': Circuits of City Surveillance since September $11^{\text {th }}$. International Journal of Urban and Regional Research, 27(3): 666-678.

Lyon, D. (2001) Surveillance Society: Monitoring Everyday Life. Buckingham, UK: Open University Press.

McCahill, M. (2002) The Surveillance Web: The Rise of Visual Surveillance in an English City. Cullompton, Devon, UK: Wilan Publishing.

Marx, G. T. (2005) Some Conceptual Issues in the Study of Borders and Surveillance. Zureik, Elia and Mark Salter (eds). In Who and What Goes There? Global Policing and Surveillance. Cullompton, Devon, UK: Willan Publishers.

Marx, G. T. (2001) Murky Conceptual Waters: The Public and the Private. Ethics and Information Technology, 3(3): 157-169.

Marx, G. T. (1988) Undercover: Police Surveillance in America. Berkeley: University of California Press.

Norris, C. and G. Armstrong. (1999) The Maximum Surveillance Society: The Rise of CCTV. Oxford, UK: Berg.

Phillips, N., T. Lawrence and C. Hardy. (2004) Discourse and Institutions. Academy of Management Journal, 29(4): 635-653.

Rule, J. (1973) Private Lives, Public Surveillance. London: Allen-Lane. 
Rule, J., D. MacAdam, L. Stearns, and D. Uglow. (1980) The Politics of Privacy: Planning for Personal Data Systems as Powerful Technologies. New York: Elsevier.

Smith, D. E. (2005) Institutional Ethnography: A Sociology for People. Walnut Creek, Calif.: Alta Mira Press.

Smith, D. E. (2001) Texts and the Ontology of Organizations and Institutions. Cultures, Organizations, and Societies, 7(2): 159-198.

Smith, D. E. (1999) Writing the Social: Critique, Theory, and Investigations. Toronto: University of Toronto Press.

Smith, D. E. (1992) Sociology from Women's Experience: A Reaffirmation. Sociological Theory, 10(1): 88-98.

Smith, D. E. (1990) Texts, Facts, and Femininity: Exploring the Relations of Ruling. New York, NY: Routledge.

Smith, D. E. (1987) The Everyday World as Problematic: A Feminist Sociology. Toronto: University of Toronto Press.

Smith, D. E. (1984) Textually Mediated Social Organization. International Social Science Journal, 36(1): $59-75$.

Taylor, J. R., F. Cooren, H. Giroux, and D. Robichaud (1996) The Communicational Basis of Organization: Between the Conversation and the Text. Communication Theory, 6(1): 1-39.

Taylor, J. R. and E. J. Van Every. (1993) The Vulnerable Fortress: Bureaucratic Organization in the Information Age. Toronto: University of Toronto.

Urry, J. (2003) Global Complexity. Malden, MA : Polity

Walby, K. (2006) Locating Televisual and Non-Televisual Textual Sequences with Institutional Ethnography: a Study of Campus and Apartment CCTV Security Work. Forthcoming in Culture and Organization, 13(1).

Walby, K. (2005) How Closed-Circuit Television Surveillance Organizes the Social: an Institutional Ethnography. Canadian Journal of Sociology, 30(2): 189-215.

Weber, M.. (1983) The Nature of Modern Capitalism. In S. Andreski (ed.) Max Weber on Capitalism. Bureaucracy and Religion: A Selection of Texts. London: George Allen \& Unwin.

Weber, M. (1968) Volume Three of Economy and Society: An Outline of Interpretive Sociology. G. Roth, and C. Wittich (eds.). New York: Bedminister Press. 